\title{
NOVAS TECNOLOGIAS, MÍdIAS E AS PRÁTICAS DE LEITURA DO CÂNONE NA ESCOLA
}

\author{
Pedro Henrique Pereira
}

\begin{abstract}
RESUMO
Este artigo discorrerá sobre a presença das novas tecnologias e das mídias nas aulas de literatura. $\mathrm{O}$ estudo procura explorar o uso do hipertexto e das multimodalidades para a construção de práticas de leitura mais significativas, promovendo os leitores como sujeitos-atores e críticos.
\end{abstract}

PALAVRAS-CHAVE: prática leitora; mídias; novas tecnologias.

\section{Considerações iniciais}

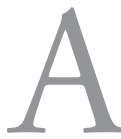

utilização das mídias, proporcionadas pelas novas tecnologias, no espaço escolar é tema de diversas discussões entre professores, pesquisadores, pais e alunos. Dentro desses debates, é preciso olhar para as possibilidades de aproximação das novas tecnologias nas práticas de leitura do cânone literário em ambientes escolares. Baseado nessas questóes, esse estudo procura compreender os impactos que as mídias acarretam no processo de ensino-aprendizagem da leitura em língua materna e apropriação de suas literaturas, percorrendo caminhos bastante amplos e maleáveis para que as reflexóes aqui feitas possam se adaptar às diferentes áreas do conhecimento abordadas no ensino regular. A pesquisa levou também à criação de uma sequência didática que mobiliza diferentes linguagens para a significação de um texto literário.

Esse estudo se faz necessário não somente pela relevância que as mídias alcançaram na sociedade contemporânea, mas também em como elas podem participar de açóes educacionais para a formação de leitores críticos e for- 
madores de discursos próprios. Em um contexto em que as mídias são vistas como meios de alienação, é preciso compreendê-las melhor, demonstrando que essas podem ajudar o professor e os alunos em suas práticas leitoras, não sendo apenas instrumentos de dominação.

O fator que gerou essa discussão apareceu pela necessidade e tentativa de atualizar os protocolos de leitura e modificar as formas tradicionais de ensino, que parecem não funcionar tão bem: a escola tem sido vista por muitos como uma instituição antiquada e falida. Alunos e professores parecem estar desmotivados com os processos de ensino-aprendizagem bastante estruturalistas e descontextualizados de suas realidades sociais. O uso das mídias e das novas tecnologias pode ajudar na melhoria desse processo.

Nessa pesquisa, procuro entender como essas novas tecnologias chegam até a escola e se estão, de fato, presentes no dia-a-dia escolar. Baseado em estudos sociológicos, linguístico-discursivos e literários - Lévy (1993;1999); Setton (2011); Rojo (2009;2012); Perrone-Moisés (2000); entre outros -, além de minha experiência como professor e no que pude observar em meus ambientes de trabalho, investiguei de quais recursos a instituição escolar se apropria para a produção de conhecimento de seus alunos. Ademais, também é importante investigar como professores e alunos podem trabalhar em conjunto para desenvolverem atividades, utilizando novas tecnologias digitais (sites, softwares, aplicativos, plataformas de cursos online, e-books, etc.).

$\mathrm{O}$ artigo procurará abordar as práticas de leitura da literatura canônica, utilizando-se das diferentes mídias e tecnologias de uso cotidiano (como a Internet, a mídia televisiva e o celular). Como atividade propícia ao uso dessas novas tecnologias para a educação, explorar-se-á o hipertexto digital, buscando compreender quais são os protocolos de leitura e produção que permeiam essa prática que parece bastante significativa para o momento de ensino-aprendizagem. Além de refletir sobre como a sociedade se adapta a essas novas possibilidades de leitura e construção/aquisição de conhecimento, também destacar-se-á o papel da multisemiose: a possibilidade de diferentes linguagens (verbais ou não) reunidas para um conhecimento mais significativo e próximo da realidade do aluno.

A fim de que os professores - algumas vezes, não muito familiarizados com o universo digital na/para educação - tenham mais segurança no uso de diferentes fontes em suas aulas, é de grande importância refletir sobre como as 
tecnologias digitais têm ingressado nas práticas de ensino. Assim feito, tornase possível propor atividades e maneiras de se utilizar as tecnologias dentro da sala de aula, estreitando as relaçóes entre professores e alunos e auxiliando os docentes em práticas de ensino-aprendizagem mais significativas.

O percurso argumentativo desta reflexão está organizado em três eixos. No primeiro, serão abordadas algumas ideias a respeito do hipertexto, tanto pela Sociologia, quanto pela Linguística, procurando relacioná-lo ao uso das Tecnologias de Informação e Comunicação (TIC) na escola e à multisemiose dos textos. No segundo, discutir-se-á sobre a literatura no espaço escolar e sua importância na construção de leitores críticos. Na última seção, uma sequência didática será apresentada como possível prática dessa transformação da leitura literária em uma leitura hipertextual.

\section{A multimodalidade e o hipertexto}

$\mathrm{O}$ advento das novas tecnologias digitais trouxe à sociedade contemporânea ferramentas de fácil utilização que possibilitam a produção de novas modalidades de textos (no sentido mais amplo da palavra). Além da rápida produção, a tecnologia também permitiu que essas novas produçóes fossem empregadas em larga circulação e obtivessem fácil visualização. No mundo contemporâneo, as produçóes textuais passaram a congregar, com maior frequência, sistemas verbais e não-verbais, ampliando as possibilidades de construçóes de sentido.

Esses sistemas simbólicos representam matéria de grande utilidade e importância para as mídias. Estas podem ser compreendidas como os meios de comunicação de massas, englobando as mercadorias culturais transmitidas por eles. A TV, o rádio, os celulares, os jornais, as revistas, a web e outros são bons exemplos abarcados pelas mídias. Além do mais, segundo Setton (2011), a mídia "pode ser mais que um instrumento de comunicação e integração social. Pode ser um instrumento ideológico, ou, em outras palavras, um instrumento de poder" (SETTON, 2011, p. 26).

Circulando constantemente no dia-a-dia da sociedade, as mídias podem determinar comportamentos sociais. Por meio de um processo educativo, ou socialização, elas transmitem, negociam e apropriam uma série de conhecimentos que mantêm e transformam os diversos grupos sociais. Funcionam, praticamente, como um possível quarto poder: além do Executivo, Judiciário 
e Legislativo, teríamos o Midiático.

Esse novo panorama social gera desafios para o momento de ensino-aprendizagem dentro do ambiente escolar que ainda se encontra em períodos de turbulência, visto que não são todas as escolas que conseguem se adaptar e abordar as produçóes midiaticas em suas realidades. Mas por que seria tão importante a presença das mídias e das novas tecnologias no espaço escolar?

A escola é um espaço para o fenômeno social de democratização, onde se deve desenvolver o processo de educar, ou ler o mundo em suas diferentes linguagens. Se levarmos em consideração que a educação prevê um objetivo em função de ideologias, de culturas e da sociedade, podemos observar que é interessante para essa ação social também abordar as mídias, uma vez que estão presentes no cotidiano da sociedade.

Portanto, se temos um mundo onde grande parte dos textos são criados a partir da congregação de diferentes linguagens, é preciso que a escola permita que o aluno tenha um contato efetivo e significativo com esses tipos de produçóes: é preciso um ambiente escolar que, além do olhar para as mídias, trabalhe o multiletramento.

Hoje podemos falar dos multiletramentos na escola. Muitos pesquisadores e educadores têm evidenciado o quão importante se faz uma nova pedagogia na educação. Este conceito:

aponta para dois tipos específicos e importantes de multiplicidade presentes em nossas sociedades, principalmente urbanas, na contemporaneidade: a multiplicidade cultural das populaçóes e a multiplicidade semiótica de constituiçáo dos textos por meio dos quais ela se informa e se comunica (ROJO, 2012, p. 13).

A escola necessita se constituir como um local de inclusão social, e os multiletramentos podem contribuir para isso. Assim, promove-se a introdução de novos gêneros para o ensino de língua materna e suas literaturas. Relembramos que os PCN já buscam uma reflexão sobre as aulas de língua materna em que é preciso desenvolver competências comunicativas que levam o aluno ao domínio da língua oral e escrita. Constitui-se o texto como unidade de ensino e o gênero como objeto a ser estudado.

Assim pensado, o processo de ensino-aprendizagem terá influências do 
contexto local, considerando aspectos socioeconômicos, históricos e políticos, de modo que cada comunidade apresente diferentes padróes de letramento. Será importante conceber um ensino que leve em consideração "os usos e práticas sociais da linguagem.” (ROJO, 2009, p. 98). Vê-se a importância da contextualização das atividades pensadas pelo professor em relação aos seus usos sociais, podendo utilizar as mídias para tal.

Dominar as múltiplas linguagens de que as mídias se utilizam permite que os alunos tenham uma autonomia intelectual e não sejam meros reprodutores de discursos da classe dominante, apagando suas identidades. A educação os torna seres livres para construírem seus próprios discursos. Se temos esse objetivo de libertação, é importante que a escola promova uma mediação no contato com as mídias, que podem ser amarras em uma sociedade de alienação e massificação.

Nesse universo de multimodalidades, a experiência do hipertexto se torna muito significativa. Tomando texto em seu sentido mais amplo (englobando sons, imagens, ou qualquer outro sistema semiótico), podemos pensar a reunião dessas diferentes linguagens como um hipertexto. "O hipertexto é constituído por nós (os elementos de informação, parágrafos, páginas, imagens, sequências musicais etc.) e de links entre esses nós, referências, notas, ponteiros, 'botóes' indicando a passagem de um nó a outro" (LÉVY, 1999, p. 56). Percebe-se, portanto, que a leitura de um hipertexto não se dá de maneira linear, mas em rede, e pode mobilizar diferentes linguagens.

Esse tipo de leitura não seria tấo diferente da leitura de um texto que estabeleça diversas conexóes, como por exemplo livros com imagens, gráficos ou notas de rodapé, que não são textos digitais necessariamente. No entanto, a grande diferença que o suporte digital confere ao hipertexto são maiores possibilidades na combinação de diferentes linguagens e a rapidez com que elas podem acontecer. De acordo com Pierre Lévy (1999), “o hipertexto digital seria definido como informação multimodal disposta em uma rede de navegação rápida e intuitiva" (LÉVY, 1999, p. 56, grifo do autor).

Assumindo essas ideias, nota-se que os protocolos de leitura são alterados. Os participantes da comunicação por intermédio do hipertexto ora estão sob o papel de leitor; ora, de autores. Isso acontece devido à natureza metamórfica dos hipertextos que mantêm a rede em construção e renegociaçóes constantes. Em outro estudo, Lévy (1993) se atenta a essas possibilidades de 
escrita e leitura:

estamos hoje tão habituados com esta interface que nem notamos mais que existe. Mas no momento em que foi inventada, possibilitou uma relação com o texto e com a escrita totalmente diferente da que fora estabelecida como manuscrito: possibilidade de exame rápido do conteúdo, de acesso não linear e seletivo do texto, de segmentação do saber em módulos, de conexões múltiplas a uma infinidade de outros livros graças às notas de pé de página e às bibliografias (LÉVY, 1993, p. 20).

Pensando no momento de ensino-aprendizagem, parece essencial que a escola se prepare para o uso do hipertexto (digital) entre os alunos, visto que esse tipo de comunicação já se encontra infiltrado na sociedade contemporânea. Ademais, como temos uma espécie de texto em que o aluno se torna também autor, a escola passa a ser um ambiente de produção de conhecimentos muito mais significativo, onde professores e alunos estão engajados para não só o consumo, mas também a produção de significados. A inserção desse hipertexto digital é facilitada pela presença das TIC em âmbito escolar.

A defesa de uma educação a partir do hipertexto também é encontrada em Lévy:

o hipertexto ou a multimídia interativa adéquam-se particularmente aos usos educativos. É bem conhecido o papel fundamental do envolvimento pessoal do aluno no processo de aprendizagem. Quanto mais ativamente uma pessoa participar da aquisiçâo de um conhecimento, mais ela irá integrar e reter aquilo que aprender. Ora, a multimídia interativa, graças à sua dimensão reticular ou não linear, favorece uma atitude exploratória, ou mesmo lúdica, face ao material a ser assimilado. É, portanto, um instrumento adaptado a uma pedagogia ativa (LÉVY, 1993, p. 24).

Fica claro que a presença das TIC na educação é bastante expressiva, promovendo uma revolução nas estruturas e métodos de ensino. Tendo em 
vista essas novas possibilidades de ensino-aprendizagem por meio de novas tecnologias, passo à discussão dos espaços da leitura literária na escola.

\section{Escola, literatura e leitura}

No poema "Aula de Português", Carlos Drummond de Andrade se debruça sob o velho embate travado entre a linguagem oral e a escrita. De forma bastante poética, o autor expressa a dificuldade que a maioria dos estudantes apresenta/sente quando são inseridos no universo da palavra escrita, complexificada ainda mais no momento em que são apresentados à literatura canônica.

"É difícil 'ler" - enunciou João Barbosa (1994, p. 22) em depoimento a um seminário. Os processos para a aquisição da linguagem escrita, que é o meio pela qual se dá a leitura clássica, são vividos durante todo o percurso da vida escolar de uma pessoa e, ainda assim, as chances de construção de um leitor-competente não são totalmente garantidas: basta abrir um jornal para se notar quão deprimente é o número de alunos que náo conseguem praticar uma boa leitura.

Nas escolas públicas brasileiras, o ensino da língua escrita já está defasado desde os ensinos primários e secundários, como aponta Leyla Perrone-Moisés (2006, p. 18). Os alunos entram em contato com o texto literário, antes mesmo de possuir a preparação prévia necessária. Sem a apropriação adequada das ferramentas de leitura, o leitor encontra-se ainda mais perdido, quando esse "ler" se desdobra em "ler literatura".

A autora sustenta essa ideia ao colocar que "os textos literários são aqueles em que a linguagem atinge seu mais alto grau de precisão [...]" (PERRONE-MOISÉS, 2006, p. 27). Muitos estudiosos tentam conceituar Literatura como um certo "estranhamento da língua", um uso da linguagem que não se encontra na vida cotidiana. Tem-se um texto pensado e elaborado a partir do árduo trabalho do escritor e, consequentemente, a leitura também será trabalhosa.

As próprias diretrizes do ensino brasileiro $(\mathrm{PCN})$ já preveem essa complicação encontrada na obra literária e, para facilitar o acesso, propóem o uso de uma literatura simplificada, chegando a substituí-la por adaptaçóes, resumos

1 Disponível em: http://drummond.memoriaviva.com.br/alguma-poesia/aula-de-portugues/ Acesso: 28/10/2015 
e simulacros. Essa literatura facilitada visará apenas o ensino de seu contorno externo, limitando-se a apreciaçôes bibliográficas ou histórico-contextuais, por exemplo.

Osakabe (2008) explica que essa facilitação acontece devido à tentativa de democratização da cultura, desvalorizando o critério estético da arte. Porém, isso não passa de uma ilusão igualitária, em que, ao invés de preparar o aluno para enfrentar as dificuldades propostas pelos textos literários, assume-se que ele não é detentor dessa capacidade e a suprime com uma obra facilitada.

Nesse sentido, priva-se o leitor do contato com a segunda possibilidade da linguagem que Perrone-Moisés (2006) apresenta em sua segunda justificativa para o ensino literário: além de atingir um elevado grau de precisão, a linguagem também apresenta sua maior potencial de significação. Sem o contato com a versão original, o estudante de literatura não acessa a infinidade de interpretaçóes possíveis da obra artística.

A intenção de formar cidadãos críticos e pensantes é vetada nessa concepção de ensino literário. Como conclui Osakabe, "é a assimilação e superação das tensóes que dá sentido à educação e não seu escamoteamento que só faz confinar, numa grande sociedade paralela, um simulacro de cidadãos." (OSAKABE, 2008, p. 49)

Para continuar a comprovação da importância literária na escola, Perrone-Moisés (2006) ainda coloca que "a significação, no texto literário, não se reduz ao significado (como acontece nos textos científicos, jornalísticos, técnicos), mas opera a interação de vários níveis semânticos e resulta numa possibilidade teoricamente infinita de interpretaçôes." (PERRONE-MOISÉS, 2006, p. 27-28). Nota-se que essa justificativa já estava prenunciada na que foi comentada anteriormente, explicando qual seria a máxima significação alcançada pela literatura.

A leitura não se prende apenas a aspectos linguísticos, ou à mera decodificação. Sua prática abrange esferas discursivo-sociais que estão dialeticamente presentes no texto. E essas relaçóes se mostram infinitas, tendo em vista a longevidade da literatura e suas diferentes apreciaçóes ao longo da história crítico-literária. A leitura permite a construção de novos sentidos a cada vez que é praticada.

A literatura torna-se ainda mais significativa, por fazer com que essas interpretaçóes sejam formas de crítica e de compreensão do mundo. Barbosa 
(1994) trata o escritor como um ser que sente vontade dessa percepção da realidade, além da possibilidade de recriá-la. A literatura, no papel de arte educativa, estabelece o meio que torna esses desejos legíveis.

Assim, "a Escola tem de ajudar na discriminação, tem de dar elementos para avaliação, mas, mais do que isso, tem de mostrar ao aluno, passar para ele, que a arte em geral - e a literatura em particular - é um jogo, que contém elementos lúdicos fundamentais." (BARBOSA, 1994, p. 26). O ensino de literatura torna-se essencial para que o leitor apreenda os discursos que a obra literária mobiliza.

A demonstração da particularidade do texto literário pelo professor permite ao aluno que se torne capaz de analisá-lo. Habilitado literariamente, o leitor pode, a partir dos significados produzidos, construir seu próprio discurso, que o posicionará socialmente. $\mathrm{O}$ ensino de literatura oferece ao aluno o exercício da liberdade: "liberdade no uso da linguagem, escleorosada e estereotipada no uso cotidiano, e liberdade do imaginário, oposto a uma suposta fatalidade da história.” (PERRONE-MOISÉS, 2000, p. 351).

Em "Literatura para quê?", Antoine Compagnon (2009) também apresenta a literatura como esse espaço de liberdade e emancipação. O pesquisador estabelece duas perguntas sobre a literatura francesa moderna e contemporânea que acabam por se estender à literatura em geral: por que e como falar da literatura? Para o estudioso, o "como" parece mais fácil de responder, então decide começar por ele. Compagnon acredita em duas possibilidades de abordagem da literatura: uma tradição teórica que toma a literatura como "una e própria” (COMPAGNON, 2009, p. 15) e outra histórica que "encara a obra como outro, na distância de seu tempo e de seu lugar" (COMPAGNON, 2009 , p. 15). O autor também propóe um breve passeio histórico, mostrando como a literatura vai perdendo seu poder de justificação social: tem-se um percurso gradativo da utilidade (viés clássico de deleite e instrução) à inutilidade (com a pós-modernidade e o "impoder") da literatura.

Compagnon parece se afeiçoar mais a um momento intermediário e romanesco de justificativa da literatura aliado à filosofia moral. Dessa forma, a literatura se justificaria por ser uma espécie de emplastro para a fragmentação da existência humana, trabalhando com a emoção e a empatia em vista da problematização da vida: "Exercício de reflexão e experiência da escrita, a literatura responde a um projeto de conhecimento do homem e do mundo." 
(COMPAGNON, 2009, p. 31). O autor parece depositar todo o poder à literatura, sendo ela - como o próprio afirma - não a única, mas a mais eficaz; ideia bastante semelhante às discussóes dos filósofos clássicos, como Platão e Horácio, sobre qual das artes seria mais eficiente na representação do real (da vida). A literatura apresenta-se como um "poder emancipador" que pode fazer-nos mais humano e "(..) nos tornará (...) melhores." (COMPAGNON, 2009, p. 64). Assim vista, ela começa a se assemelhar, talvez um tanto demasiadamente, à ideia platônica do amor como o caminho da transcendência que nos torna superiores.

A literatura poderia ser entendida facilmente como Fedro discursou sobre o amor em "O Banquete": o meio de melhora moral. Em suas palavras, "[...] Eros é o mais antigo dos deuses, o mais honrado, o mais poderoso para levar os homens à virtude e à felicidade nesta vida e depois da morte." (PLATÃO, 2013, p. 41, grifo meu). Mais adiante, ainda podemos encontrar Sócrates dizendo que "para a aquisição desse cabedal, nenhum colaborador melhor do que Eros poderá favorecer a natureza humana. Enfatizo a necessidade de honrar Eros." (PLATÃO, 2013, p. 113, grifo meu).

Por esses pequenos excertos, parece possível a simples troca de Eros por Literatura. Tomando a perspectiva de Compagnon, o que é a literatura senão o caminho à virtude e o favorecimento da natureza humana, ou nossa humanizaçáo? Um pouco mais a fundo, ainda podemos pensar na palavra "cabedal". Segundo o dicionário Aurélio, de forma figurativa, o termo representa "as qualidades intelectuais e/ou morais de alguém." (FERREIRA, 2008, p. 194). Com as devidas substituiçóes, ficamos com a literatura como a melhor colaboradora para a aquisição dessas qualidades virtuosas. Assim, "[...] ela nos torna, portanto, sinceros e verdadeiros, ou simplesmente melhores." (COMPAGNON, 2009, p. 36). Tornamo-nos, então, cidadãos livres, aptos a exercer nosso "poder emancipador".

Não obstante, Barthes (2013) também acredita na literatura como um lugar de liberdade. Todavia, ele deposita o poder - e em relação de opressão - à linguagem, ou a própria língua; portanto, a força libertária da literatura está no "trabalho de deslocamento que ele [autor] exerce sobre a lingua." (BARTHES, 2013, p. 18; grifo meu). O poder literário já não está mais tão intrínseco à problematizaçáo da vida, mas sim à linguagem: a literatura passa a ser entendida como um "logro magnífico que permite ouvir a língua fora do poder $[\ldots]$ " 
(BARTHES, 2013, p. 17). Ainda assim, Barthes não tira a tamanha eficácia da literatura, afirmando que todas as ciências podem ser encontradas na literatura, fazendo dela uma disciplina essencial, em que tudo se pode aprender.

A grande contribuição que estas ideias trazem é um estudo literário conjugado à semiologia, ou a ciência dos signos. Além do social, volta-se ao texto em si: o "índice do despoder" (BARTHES, 2013, p. 36). Não há dúvidas que a representação do real (da vida) encontra-se na literatura e, com esse tratamento teórico barthesiano, o estudo da obra literária se focará mais nas estruturas e nos signos que trazem a aparência de verossimilhança ao texto, uma vez que o autor acredita que o real não é representável, mas, ainda assim, objeto de desejo da literatura.

Como Compagnon afirma, "o espaço da literatura tornou-se mais escasso em nossa sociedade há uma geração" (COMPAGNON, 2009, p. 25) e, talvez, a melhor forma de conquistar os alunos para a importância do estudo literário não seja afirmando que a literatura será a única a conseguir problematizar, compreender ou representar a vida. O cinema, a pintura, a música ou outras artes também não problematizam a realidade e tornam o homem mais humano? É mesmo necessário somente a literatura para tal trabalho? Hoje, "[...] a reflexão sobre o mundo e o homem pela literatura não é a mais corriqueira.” (COMPAGNON, 2009, p. 57)

No entanto, o mérito literário não deve ser denegrido, mas é preciso dosar essa necessidade exclusivista da literatura. No âmbito da linguagem/língua, a literatura, assim como Barthes pensa, é o grande destaque; e, considerando que a língua é o meio expressivo mais utilizado pela sociedade e o "objeto em que se inscreve o poder" (BARTHES, 2013, p. 12), o ensino dessa arte se faz necessário para que o aluno domine sua prática. Assim, podemos chegar ao pensamento de Compagnon que a leitura torna a vida mais cômoda e clara para os que a praticam.

Assumir que a literatura não é a única e, nem sempre, a mais poderosa, pode mostrar aos alunos a real importância e lugar da literatura, não deixando de ser uma disciplina que deva ser estudada. Outras artes e formas de expressão também podem representar e questionar a vida, conferindo "poder emancipador", mas é ela quem realiza isso, focando no uso das palavras (dos signos). Dessa forma, se fará ainda mais verdadeira a afirmação que encerra o livro de Compagnon: "Ela [literatura] sofre concorrência em todos os seus usos e não detém o monopólio sobre nada, mas a humildade lhe convém e seus poderes 
continuam imensos." (COMPAGNON, 2009, p. 72).

As TIC podem colaborar para a apreciação dessa literatura emancipadora, mas não exclusivista. Com a presença midiática, faz-se possível uma construção híbrida da literatura, congregando a ela outras artes (como o cinema, a música, as artes visuais entre outras). Constrói-se, portanto, uma literatura hipertextual, que proporcionará aos alunos uma experimentação aumentada do literário por diferentes caminhos.

Assim, temos construído o grande e novo desafio da escola: abordar as mídias e as novas tecnologias nas práticas leitoras, fazendo delas produçôes que levem os alunos à libertação e não à sua alienação. Na próxima seção, proponho uma sequência didática que busca transformar e explorar a literatura como um texto hipertextual e multimodal, possibilitando sua maior significação.

\section{A literatura hipertextual e multimodal}

Essa terceira e última seção propóe uma possível sequência didática ${ }^{2}$ que pode ser utilizada como inspiração para professores pensarem em atividades de leitura que congregam o texto literário e a leitura hipertextual, utilizando diferentes mídias e tecnologias. Esta seção surge com o intuito de mostrar como é possível modificar os protocolos de leitura, saindo de uma literatura linear para outra hipertextual e multifacetada, conforme defendido na seção anterior.

O percurso teórico aqui traçado levou a reflexóes de possibilidades de aproximar mídias, novas tecnologias, diferentes linguagens e leitura literária. Essas reflexóes materializaram-se em uma sequência didática que aborda a prática de leitura (hipertextual e multimodal) de obras canônicas nas aulas de literatura. A sequência encontra-se em anexo e pode ser fonte de inspiração para que professores pensem em novas práticas de leitura. Ressalto que não há receitas fixas para se seguir e preparar uma aula; cabe ao professor pensar e adaptar os conteúdos de acordo com cada uma de suas turmas e a realidade que as cerca.

Como a proposta lida com uma leitura hipertextual, multimodal e digital, é importante que a escola esteja bem preparada para que todas as etapas possam acontecer. Essa modificação nos protocolos de leitura acaba por in-

2 Agradecimentos especiais às professoras e pesquisadoras Amanda Topic Ebizero, Vanessa Caspon e Nathalia Lima Silva, que participaram da produção dessa sequência didática. 
fluenciar no cotidiano e estrutura escolar. Pode-se pensar, por exemplo, que o uso de dispositivos eletrônicos e digitais na escola requer a criação de uma equipe técnica que fará a manutenção desses equipamentos. Além disso, ainda é preciso a compra de computadores, projetores, assinaturas de internet, equipamentos de som, treinamento para professores, adaptaçóes de material que, somados, gerarão novos custos ao financeiro da escola. Mais que a inserção da tecnologia, se faz também preciso pensar em seu entorno social. Winner (1986) diz que:

O que importa não é a tecnologia em si, mas o sistema social ou econômico no qual ela está inserida. Esta máxima, a qual em si ou segundo variaçóes é a premissa central de uma teoria que pode ser chamada de determinação social da tecnologia, tem uma sabedoria óbvia. Ela serve como um corretivo necessário para aqueles que estudam, sem o devido olhar crítico, coisas como "o computador e seus impactos sociais", mas se esquecem de olhar, por trás dos dispositivos técnicos, as circunstâncias sociais de seu desenvolvimento, emprego e uso (WINNER,1986, p. 20-21).

Fica claro que a simples instalação de um projetor ou computador não é sinônimo de uma tecnologia funcionando bem na comunidade escolar. Diversas circunstâncias devem ser levantadas, questionadas e analisadas para que os dispositivos, de fato, gerem desenvolvimento dentro da sala de aula. No entanto, essas dificuldades técnicas não podem ser empecilho para que a construção de significados aconteça.

A sequência didática (em anexo) visa, além da aproximação entre mídias, novas tecnologias e leituras literárias, à possibilidade da presença da literatura estrangeira no espaço escolar, nesse caso a americana. $\mathrm{O}$ autor escolhido foi Edgar Allan Poe e a obra a ser estudada é seu famoso poema "O Corvo" em tradução de Fernando Pessoa. A aula se compóe de recursos midiáticos como curta-metragem e documentário, além do uso de áudios e imagens. O trabalho final da sequência pede aos alunos uma produção multimodal que objetiva a expressão das suas leituras da obra e dos conhecimentos literários construídos.

A proposta é feita a alunos do $2^{\circ}$ ano do Ensino Médio, mas pode ser 
adaptada para outras séries. Tendo em vista uma exploração mais profunda e crítica da literatura, pensou-se nessa série, pois os alunos já teriam algum contato prévio com o discurso literário, o que os ajudaria na hora da leitura. Também foi pensada uma dedicação de tempo maior (um total de seis aulas) para que a obra fosse bastante explorada e houvesse tempo hábil para as experimentaçóes multimodais e hipertextuais do poema.

A sequência está baseada nos diferentes processos de leitura para o letramento literário propostos por Rildo Cosson (2012). Portanto, os alunos passam por uma motivação de leitura e introdução da obra, é feita uma primeira leitura seguida de um momento para interpretaçóes e, finalmente, chega-se à avaliação e expansão dos conteúdos. Cada uma dessas etapas estruturam a sequência de aulas propostas e o que acontece em cada uma delas está descrito aula por aula.

\section{Considerações finais}

Como pôde ser notado através da explanação teórica e da sequência proposta, as tecnologias podem causar distintos impactos: para alguns, podem ser aspectos positivos e relevantes à educação e, para outros, podem ser apenas um "diferencial", mas nada que possa ser transformador ou portador de uma realidade social significativa para o aluno, preferindo assim o quadro negro e o giz.

Infelizmente, as escolas ainda estão em déficit quanto à construção de conhecimento proporcionado pelas novas tecnologias, o que acaba sendo um processo moroso e pouco visado. Porém, é papel do professor conhecer a realidade do aluno e saber entender que as tecnologias fazem parte de suas vidas, e que é de extrema relevância usá-las em favor da educação.

Os professores que estiverem dispostos a aprender e utilizar as novas tecnologias precisam observar seus contextos e perceberem que diferentes práticas de ensino-aprendizagem podem ser requeridas: pode-se fazer o estudo das tecnologias em si (o ensino de programação, por exemplo), como também a construção de conhecimento com e por meio delas. Os objetivos de ensino definirão qual(is) abordagem(s) seguir. Ademais, é preciso ter em mente que incorporar tecnologias em sala de aula não significa a mera instalação de algum aparelho no espaço físico escolar. É preciso que a escola considere as circunstâncias sociais que serão levantadas a partir da presença de tais dispositivos e se 
mobilize para que as tecnologias expressem mudanças consideráveis no ensino.

Como forte exemplo, o artigo buscou apresentar e explorar o hipertexto, que está bastante presente na sociedade e demonstra ser um espaço de grande significação tanto para alunos quanto para professores, fazendo deles sujeitos-autores e produtores de conhecimentos. Apesar do estudo ter permeado o universo do ensino de literaturas e práticas leitoras, o hipertexto pode ser utilizado para as mais diferentes disciplinas, uma vez que se pode abranger conteúdos diversos por meio dele.

Ressalto, por fim, a importância da presença das tecnologias em ambiente escolar que o artigo buscou explorar. No entanto, coloco ainda mais em realce que elas não são soluções definitivas para os problemas na educação. As TIC podem ser um caminho, uma alternativa para um melhor rendimento, para uma boa compreensão e uma maior criticidade que os alunos construirão para a sua formação como sujeitos produtores de discursos e não como meros reprodutores de textos. Apesar de muito benéficas quando bem usadas, as novas tecnologias não salvam/salvarão a educação (brasileira).

\section{Referências}

BARBOSA, João Alexandre. "Literatura nunca é apenas literatura". Série Ideias. n. 17. São Paulo: FDE, 1994. p. 21-26.

BARTHES, Roland. Aula (trad. Leyla Perrone-Moisés). São Paulo : Cultrix, 2013 COMPAGNON, Antoine. Literatura para quê?? (trad. Laura Taddei Brandini). Belo Horizonte: Editora UFMG, 2009.

COSSON, Rildo. Letramento Literário: teoria e prática. São Paulo: Editora Contexto, 2012

LÉVY, Pierre. Cibercultura (trad. Carlos Irineu da Costa). Rio de Janeiro: Editora 34, 1999.

- As Tecnologias da Inteligência: o futuro do pensamento na era da informática (trad. Carlos Irineu da Costa). São Paulo: Ed. 34, 1993.

MINISTÉRIO DA EDUCAÇÃO. Parâmetros Curriculares Nacionais - Ensino Médio. Área de Linguagens, Códigos e suas Tecnologias. Brasília: Secretaria de Educação Média e Tecnológica/MEC, 1999

Tecnologia na Educação. Disponível em: <http://revistaescola.abril.com.br/ blogs/tecnologia-educacao> Acesso em: 29 out. 2014. 
OSAKABE, Haquira. "Poesia e indiferença”. In: Leituras Literárias: discursos transitivos. PAIVA, A.; MARTINS, A.; PAULINO, G.; VERSIANI, Z. (orgs.). Belo Horizonte: Ceale/ Autêntica, 2008. p. 37-54

PERRONE-MOISÉS, Leyla. "Literatura para todos". In: Literatura e Sociedade. n. 9. São Paulo: DTLCC - USP, 2006. p. 16-29

. "Consideração intempestiva sobre o ensino de literatura”. In: Inútil Poesia e outros ensaios breves. São Paulo: Cia. das Letras, 2000. p. 345-351.

ROJO, Roxane. Letramentos múltiplos, escola e inclusão. São Paulo: Parábola Editorial, 2009.

ROJO, Roxane. \& MOURA, Eduardo. (orgs.). Multiletramentos na escola. São Paulo: Parábola Editorial, 2012.

SETTON, Maria da Graça. Midia e educação. São Paulo: Ed. Contexto, 2010. WINNER, Langdon. Artefatos têm Politica? (trad. Fernando Manso). "Do artifacts have politics?" In. The Whale and the Reactor: a search for limits in an Age of High Technology. Chicago: The University of Chicago Press, p.19-39. $<$ http://pimentalab.milharal.org/files/2013/11/Langdon-Winner-Artefatostem-Politica.pdf>

\title{
NEW TECHNOLOGIES, MEDIA AND READING PRACTICES OF CANONICAL LITERATURE IN THE SCHOOL
}

\begin{abstract}
This article investigates new technologies, media and their presence in literature classes. The study will explore the use of hypertext and multimodalities in order to achieve more significant reading practices, promoting critical readers and actors.
\end{abstract}

Key-words: Reading practice; media; new technologies.

Recebido em: 30/10/2015 Aprovado em: 15/03/2016 


\section{ANEXOS}

\section{Proposta de sequência didática - Leitura de poesia moderna: "O corvo", de Edgar Allan Poe}

Série: $2^{\circ}$ ano do Ensino Médio

Tempo de aula previsto: 6 aulas de 50 minutos cada

Tema: leitura de poesia moderna ("O corvo", de Edgar Allan Poe - tradução de Fernando Pessoa)

Objetivo: pretende-se que o aluno do $2^{\circ}$ ano do Ensino Médio - já com alguns conhecimentos literários prévios - alcance uma habilidade leitora sensível ao gênero poético, especificamente aquele de cunho moderno. Recursos utilizados: Poema impresso em papel sulfite para cada aluno, equipamento de reprodução audiovisual, podendo ser TV ou projetor. Avaliação: Produção audiovisual da leitura dramática do poema trabalhado. Essa forma avaliativa foi escolhida tendo em vista a facilidade que os alunos possuem com as novas tecnologias e por terem a oportunidade de expressarem suas impressóes do poema com a gravaçáo. O trabalho deverá ser executado fora de sala de aula em grupos de 5 (cinco) participantes no máximo. Os alunos podem produzir gravações deles mesmos interpretando o poema ou podem produzir imagens inspiradas no poema que serão exibidas durante a leitura. A produção final deverá ser gravada em DVD ou dispositivo móvel, para exibição em sala.

\section{Etapas:}

Aula 1: motivaçóes de leitura e introduçáo

Nesta aula, incitaremos a curiosidade do aluno pela obra de Edgar Allan Poe e, especificamente, obras que tenham como temáticas o sobre-humano e o horror. Para tanto, será exibido o curta-metragem Vincent (1982), de Tim Burton, seguido de uma contextualização da vida e do período histórico-cultural do autor, através de trechos do documentário "Contos 
de Terror", da série Great Books do canal Discovery Civilization - todos os vídeos estão disponíveis online -. Com a exibição do documentário, pretende-se aproximar a obra, o momento histórico e a biografia de Poe. Vale ressaltar que, no caso do autor em questão, sua vida e obra estão, de certa forma, relacionadas. Ao final da aula, será entregue o poema aos alunos, com o intuito de buscarem um primeiro contato com o texto em casa.

\section{Aulas 2/3: leitura do poema}

A aula partirá do pressuposto que os alunos tenham lido o poema em casa. Com essa leitura, será feita uma discussão sobre as impressóes que os alunos tiveram durante a leitura. Em seguida, com as luzes apagadas - se possível - ouviremos uma leitura dramática do poema (com a tradução em português por Fernando Pessoa) por José Augusto de Almeida. Após ouvirem a narração, solicitaremos aos alunos que comentem sobre o tom do poema. A partir da definição de um tom (melancólico, sombrio, grotesco, horripilante, por exemplo), serão explicadas brevemente noçóes formais do poema (métrica, ritmo e rima) - esses aspectos podem ser apreendidos pelo professor no ensaio "A Filosofia da Composição" escrito pelo próprio autor -. Ao final da aula, pede-se uma pesquisa sobre a figura representativa do corvo e uma nova leitura do poema.

\section{Aula 4: segunda interpretação}

A aula começará com a leitura em voz alta do poema pelos alunos. Em seguida, verificaremos as pesquisas feitas em casa. As informaçóes colhidas serão discutidas pela turma e relacionadas ao poema. Com estes levantamentos, será solicitada uma avaliação, que consistirá numa gravação audiovisual contendo a leitura dramática do poema, em grupos de até 5 (cinco) pessoas. Para encerrar a aula, serão exibidas algumas ilustraçóes de Gustave Doré feitas para o poema - disponíveis online.

\section{Aulas 5/6: avaliação e expansão (uma semana após a aula 4)}

A aula iniciará com as impressôes dos alunos com a produção do trabalho. Após isto, discutiremos como toda essa trajetória se relaciona com o curta exibido na Aula 1, especialmente relacionando as interpretações do 
poema ao curta-metragem Vincent e às informaçóes quanto à biografia e ao período histórico-cultural. Ao final, assistiremos às produçóes dos alunos em sala.

Bibliografia da Sequência Didática:

COSSON, Rildo. Letramento Literário: teoria e prática. São Paulo: Editora Contexto, 2012

POE, Edgar Allan. A Filosofia da Composição. Tradução de Léa Viveiros de Castro. Rio de Janeiro: 7Letras, 2008

Anexos da Sequência Didática:

- Links:

Curta-metragem: http://www.youtube.com/watch?v=f-okS38ccpc Documentário: http:/www.youtube.com/watch?v=KpbaeVgLpVc Leitura dramática: http://www.youtube.com/watch?v=1Krv23VfGSo 